\title{
An Empirical Study on the Relationship Between Energy Consumption and GDP in China
}

\author{
Jian ZHANG ${ }^{\mathrm{a}}$, Xin $\mathrm{ZHOU}^{\mathrm{b}, \mathrm{cl}}$ \\ ${ }^{a}$ School of Economics and Management, Shanghai University of Political Science and \\ Law, Shanghai, 201701, China \\ ${ }^{b}$ School of Economics, Shanghai University, Shanghai, 200444, China \\ 'School of Languages and Cultures, Shanghai University of Political Science and Law, \\ Shanghai, 201701, China
}

\begin{abstract}
Based on the provincial panel data of China from 1990 to 2018, this paper establishes a simultaneous equation model containing exogenous variables such as capital stock, urbanization and trade liberalization to explore the causal relationship between energy consumption and economic growth. The study found that China's GDP and energy consumption influence each other, which is manifested as an endogenous causal relationship in the economic system. When the economic aggregate increases, the demand for energy has risen sharply. However, due to the low energy use efficiency production mode and environmental destruction and pollution, energy consumption shows a negative scale effect that restricts economic growth. China's economic growth is manifested in diminishing returns to scale, and the urbanization rate and trade openness have a significant impact on energy consumption.
\end{abstract}

Keywords: Energy consumption, economic growth, panel data simultaneous equations model

\section{Introduction}

Studying the relationship between energy consumption and GDP has important application value for a country's policy makers. On the one hand, the government is highly concerned about the speed of economic growth. On the other hand, the government is worried about the destruction of the environment and the excessive consumption or lack of resources. If energy consumption does not have a significant impact on GDP, the government can more easily formulate policies to protect the environment and resources without worrying about the decline in economic growth. If there is a significant relationship between energy consumption and GDP, then the policies for protecting the environment and resources will limit economic growth and hinder the improvement of residents' welfare, which makes the implementation of energy saving policies very difficult.

${ }^{1}$ Corresponding Author: Xin Zhou, School of Economics, Shanghai University, Shanghai, 200444, China; Email: zhouxin@shupl.edu.cn. 
The relationship between energy consumption and GDP has not only attracted the attention of policy makers, but also attracted the attention of many scholars. They used the data from different countries and regions in combination with various econometric methods to conduct research of the two variables, and obtained conclusions with huge differences. At present, the academic circles believe that there are four situations in the relationship between energy consumption and GDP. The first is the hypothesis of environmental protection, which believes that changes in GDP are the cause of changes in energy consumption. Therefore, any policy to protect the environment and resources will not affect the economy growth. The second is the growth hypothesis, which believes that energy consumption is the cause of GDP changes. Therefore, any policy to reduce energy consumption will limit the growth of GDP. The third is the feedback hypothesis, which believes that there is a two-way causal relationship between energy consumption and GDP. The fourth is the irrelevant hypothesis, which believes that there is no causal relationship between energy consumption and GDP.

Since previous studies have not obtained consistent and reliable conclusions, it is difficult for policy makers to decide which energy policies to adopt for economic development. Most previous empirical studies were based on single equation models that lacked economic theoretical support. The studies mainly examining the causal relationship in a single direction from independent variables to dependant variable, and lacked the discussion of the mechanism of simultaneous interaction between variables. At the same time, they used time series data for analysis. The changes in economic variables in reality often show non-stationary and nonlinear characteristics, such as production functions, etc. Therefore, the robustness of the research conclusions has been greatly questioned. Based on China's provincial panel data from 1990 to 2018, we use the panel simultaneous equation model to explore whether there is a causal relationship between energy consumption and economic growth within a endogenous system, so as to accurately formulate macroeconomic development policies to promote economic growth and improve energy use efficiency.

\section{Literature Review}

The research on the relationship between energy consumption and economic growth can be traced back to the 1970s. In Kraft \& Kraft's pioneering study in 1978, they found that GNP was the cause of changes in energy consumption by using US data from 1947 to 1974.[1] Subsequently, other scholars used time series data from different countries to conduct causal analysis on the relationship between economic growth and energy consumption (e.g., Akarca and Long 1979, [2] Akarca and Long 1980, [3] Eden and Hwang 1984 [4], Yu and Choi 1985, [5] Erol and Eden 1987 [6]). They found that the direction of influence between economic growth and energy consumption is not fixed and the research conclusions are different. In most cases, studies on the relationship between economic growth and energy consumption use ordinary least squares to estimate log-linear models and perform statistical tests on coefficients. The defect is that the nonstationary characteristics of time series data are not considered in previous studies. Therefore, their conclusion may be wrong.

In the past few decades, time series analysis methods have made rapid development and progress. During the same period, the introduction of panel data models has also improved the robustness of the estimation results. New methods beyond simple linear regression are used to study the relationship between energy consumption and economic 
growth. The researches of correlation in this period were mostly based on the EngleGranger test, Johansen cointegration test, vector error correction model and vector autoregressive model (e.g., Eden and Jin 1992 [7], Masih and Masih 1996 [8], Masih and Masih 1997 [9], Glasure and Lee 1997 [10], Asufu-Adjaye 2000 [11], Hondroyiannis etc. 2002 [12], Soytas and Sari 2003 [13], Altinay and Karagol 2004 [14], Ang 2007 [15], Ang 2009 [16], Halicioglu 2009 [17], Jalil and Mahmud 2009 [18], Apergis and Payne 2009 [19], Apergis and Payne 2010 [20], Hossain 2011 [21]). By analysing the time series data and panel data of different countries including China, the conclusions are still inconsistent. The main reason for the different research results in the above is mainly due to the different econometric methods used in the empirical analysis.

By reviewing the relevant research above, it can be found that testing the same indicators in the same country could lead to different conclusions. The reasons might be different periods of research and different methods used. Another common reason is insufficient sample data for the study. The time span of these studies using time series models is 30 to 40 years. Small sample size may lead to lower reliability of statistical tests, so that the results of the research are not consistent. In order to solve the statistical defects of the time series model due to the lack of sample size, the panel data method is applied to the study of the relationship between energy consumption and economic growth. However, the application of panel data methods has also brought new problems. Regarding different countries as a homogeneous group rather than independent individuals cannot identify the different dynamic relationships between energy consumption and economic growth. When other explanatory variables are added in the empirical models, the relationship between energy consumption and economic growth could also change due to the different levels of economic development among countries.

This paper uses China's provincial panel data to establish a simultaneous equation model to study the relationship between GDP and energy consumption. The system considers capital stock, urbanization rate, square of GDP, and trade liberalization rate as exogenous variables. It could not only improve the statistical defects caused by the lack of sample size in the time series model, but also avoids the problem of heterogeneous individuals in panel data model. It also depicts the dynamic relationship between different variables while constructing models based on economic theory and improving the statistical reliability of research results.

\section{Data and Model}

\subsection{Selection of Data and Variable}

We select data of per capita GDP, per capita energy consumption, per capita capital stock, urbanization rate, and trade openness of 30 provinces, cities, and autonomous regions in China from 1990 to 2018 (Because Tibet lacks energy consumption data, the panel data simultaneous equation model only contains data for 30 provincial units.), and establishes a panel simultaneous equation model to study the relationship between economic growth and energy consumption. Each variable uses the GDP deflator as a measure of price index to adjust the relevant variables at constant prices. In order to maintain the consistency and timeliness of the data, 2018 is selected as the base period. Among these variables, the capital stock of each province is calculated by the perpetual inventory method, the urbanization rate is calculated by the ratio of the urban population 
to the total population, and the trade openness is calculated by the ratio of the total import and export trade to GDP.

\subsection{Data Stationarity Test}

In order to construct a simultaneous equation model, we examine the stationarity of the variables by performing a unit root test at first. Since the time series data of per capita GDP, per capita energy consumption, and per capita capital stock show a strong trend, we take the logarithm of the three variables for further study. While the urbanization rate and trade openness are proportional data which no trend were shown, so their original forms were used for modeling. The PP-Fisher panel unit root test results of all five variables are shown in Table 1. lgdp represents the logarithm of per capita GDP, lec represents the logarithm of per capita energy consumption, and lcap represents logarithm of the per capita capital stock, to represents trade openness, $u r b$ represents urbanization rate. The test statistics of the level values of each variable in Table 1 are all less than the critical value of the $5 \%$ significance level, indicating that the variables are not stationary. The test statistics of the variables after the first order difference are all greater than the critical value of the 5\% significance level. The test results indicate that all variables are stable after first order difference.

Table 1. The results of PP-Fisher panel unit root test.

\begin{tabular}{cccccc}
\hline & $l g d p$ Statistic & $l e c$ Statistic & lcap Statistic & to Statistic & urb Statistic \\
\hline Level & $28.5700^{\text {a }}$ & 40.8100 & 37.1100 & 68.1500 & 70.5700 \\
1st Difference & 157.2300 & 214.3400 & 117.2400 & 567.5000 & 304.4200 \\
\hline a The Chi-square
\end{tabular}

${ }^{\text {a }}$ The Chi-square critical value of the $5 \%$ significance level is 79.0819 .

\subsection{Panel Cointegration Test}

In order to analyse the relationship between economic growth and energy consumption in a model system, it is necessary to determine whether there is a co-integration relationship between economic growth and energy consumption while per capita capital stock, trade openness and urbanization rate are taken as exogenous variables. Per capita GDP and per capita energy consumption are tested by panel co-integration. There is a cointegration relationship between $\lg d p$ and $l e c$ according to the statistical $p$ value of the trace test and the maximum eigenvalue test results in Table 2 under the significance level of $5 \%$. The simultaneous equation model can be further established.

Table 2. The results of Johansen co-integration test.

\begin{tabular}{ccccc}
\hline & Trace Statistic & Trace Prob. & Max-Eigen Statistic & Max-eigen Prob. \\
\hline None & 25.8700 & 0.0010 & 23.8900 & 0.0010 \\
At Most 1 & 1.9800 & 0.1590 & 1.9800 & 0.1590 \\
\hline
\end{tabular}

\subsection{Panel Granger Causality Test}

In order to construct a simultaneous equation model of economic growth and energy consumption, it is also necessary to examine whether there is a two-way causal relationship between per capita GDP and per capita energy consumption. If there is no two-way causal relationship between the two variables, then the simultaneous equation model cannot be constructed. Therefore, the panel data Granger test between $\lg d p$ and $l e c$ is further carried out. The statistical $p$ values of the test results in Table 3 are all less than the $5 \%$ significance level. It means that there exists a two-way causal relationship 
between per capita GDP and per capita energy consumption, and the simultaneous equation model can be further established.

Table 3. The results of panel Granger causality test.

\begin{tabular}{ccc}
\hline Null Hypothesis & F-Statistic & Prob. \\
\hline Lec does not Granger Cause $\lg d p$ & 12.4600 & 0.0000 \\
$\lg d p$ does not Granger Cause $l e c$ & 3.5100 & 0.0300 \\
\hline
\end{tabular}

\subsection{Construction and Estimation of Simultaneous Equation Model}

According to the results of various tests before, considering to establish a simultaneous equation model with a total production function equation and a Kuznets energy consumption function equation. We propose an aggregate production function model that includes the spillover effect of energy consumption on productivity. It is assumed that energy consumption is an important input factor in production, and the aggregate production function of each province is set as follows:

$$
G D P_{i t}=C A P_{i t}^{\beta}\left(A_{0} P O P_{i t}\right)^{1-\beta} E C_{i t}^{\gamma}
$$

Where $G D P_{i t}$ is the real GDP of province $i$ at time $t, C A P_{i t}$ is the real capital stock of province $i$ at time $t, P O P_{i t}$ is the population of province $i$ at time $t$, and $E C_{i t}$ is the per capita energy consumption of province $i$ at time $t, A_{0}$ is the initial technical level, $\beta$ $(0<\beta<1)$ and $\gamma(-1<\gamma<1)$ are parameters to be estimated. If $\gamma=0$, it means that energy consumption has no spillover effect on economic growth, and the aggregate production function is constant returns to scale. If $\gamma<0$, it means that economic growth is manifested as diminishing returns to scale, and energy consumption has a reverse spillover effect on economic growth. It means that the use of energy under the current production mode limits further economic development. The inefficient use of energy and the limited petrochemical resources dragged down the economic growth, and reduce the impact of other production factors on output. If $\gamma>0$, it means that the aggregate production function shows as increasing returns to scale. Energy has a positive spillover effect on economic growth. The increase in the use of energy will promote the increase in output. After taking the logarithm of all variables and adding a random disturbance term, equation (1) can be rewritten as follows:

$$
\lg d p_{i t}=c+\beta \cdot \operatorname{lcap}_{i t}+\gamma \cdot \operatorname{lec}_{i t}+u_{i t}
$$

Where $\lg d p_{i t}=\ln \left(G D P_{i t} / P O P_{i t}\right)$ is the logarithm per capita GDP of province $i$ at time $t$, lcap $_{i t}=\ln \left(C_{A} P_{i t} / P O P_{i t}\right)$ is the logarithm per capita capital stock of province $i$ at time $t$, $l e c_{i t}=\ln \left(E C_{i t}\right)$ is the logarithm per capita energy consumption of province $i$ at time $t$, $c=\ln \left(A_{0}\right)$ is the intercept term which means the initial technical level, $u_{i t}$ is the random disturbance term.

Chinese government advocates the Belt and Road Initiatives to promote international trade among the countries. They also propose urbanization within China to accelerate the transfer of rural population to urban to promote economic development and improve the living standards of residents. So that the impact of trade openness and urbanization on energy consumption and economic growth cannot be ignored. Therefore, 
a corresponding environmental Kuznets curve equation including urbanization rate and trade openness is established for energy consumption:

$$
l e c_{i t}=\beta_{0}+\beta_{1} \lg d p_{i t}+\beta_{2} \lg d p_{i t}^{2}+\beta_{3} u r b_{i t}+\beta_{4} t o_{i t}+\varepsilon_{i t}
$$

Where $l e c_{i t}$ is the logarithm per capita energy consumption of province $i$ at time $t$, $\lg d p_{i t}$ is the logarithm per capita GDP of province $i$ at time $t, u r b_{i t}$ is the urbanization rate of province $i$ at time $t, t_{i t}$ is the trade openness of province $i$ at time $t, \varepsilon_{i t}$ is the random disturbance item. The signs of $\beta_{1}, \beta_{2}$ and $\beta_{4}$ are assumed positive, indicating that the increase in GDP, urbanization rate, and trade openness will increase energy consumption. If the environmental Kuznets curve hypothesis is valid in China, the sign of $\beta_{2}$ should be negative, which means that after the economy develops to a certain extent, the total energy consumption begins to decline, and the economic growth mode changes from extensive to intensive.

The econometric methods of estimating parameters used in previous studies such as ordinary least squares method, instrumental variable method, and maximum likelihood method have their own limitations. Their parameter estimators have good statistical properties only when the model meets certain assumptions. For example, the parameter estimator of the maximum likelihood method is a reliable estimator only when the error term of the model obeys a normal distribution or a certain known distribution. The Generalized Method of Moments (GMM) does not require special assumptions of error term. It allows error terms to have heteroscedasticity and serial correlation, and does not need to know the exact distribution of the error term. The obtained parameter estimates from GMM are more realistic and robust than other parameter estimation methods. Therefore, we use GMM method to estimate the panel simultaneous equation model. The results are shown in Table 4.

Table 4. The results of simultaneous equation GMM-HAC method.

\begin{tabular}{|c|c|c|c|}
\hline \multicolumn{2}{|c|}{ The Results of Equation (2) } & \multicolumn{2}{|c|}{ The Results of Equation (3) } \\
\hline$l e c_{i t}$ & $\begin{array}{c}-0.1584 * * * a \\
(0.0529)^{\mathrm{b}}\end{array}$ & $\lg d p_{i t}$ & $\begin{array}{c}2.0813 * * * \\
(0.4275)\end{array}$ \\
\hline lcap $_{\text {it }}$ & $\begin{array}{c}0.4938 * * * \\
(0.0639)\end{array}$ & $\lg d p^{2}{ }_{i t}$ & $\begin{array}{c}-0.0623 * * * \\
(0.0203)\end{array}$ \\
\hline & & $\begin{array}{c}u r b_{i t} \\
t o_{i t}\end{array}$ & $\begin{array}{l}0.0020^{*} \\
(0.0012) \\
0.0003 * \\
(0.0002)\end{array}$ \\
\hline Intercept & $\begin{array}{c}8.0415 * * * \\
(1.2528)\end{array}$ & Intercept & $\begin{array}{c}-7.9865 * * * \\
(2.3960)\end{array}$ \\
\hline Adj. $R^{2}$ & 0.9992 & $\operatorname{Adj} . R^{2}$ & 0.9923 \\
\hline$D W$ & 1.8451 & $D W$ & 2.0105 \\
\hline
\end{tabular}

The estimation result of equation (2) shows that per capita capital stock and per capita energy consumption have a significant impact on per capita GDP. Every 1\% increase in per capita capital stock will increase per capita GDP by $0.4940 \%$. This also shows that the output elasticity of the capital stock is basically equal to the output elasticity of the population in China. The coefficient of per capita energy consumption 
$\gamma=-0.1580$ is less than zero and significant at $1 \%$ significance level. It means that in the current economic development mode, energy consumption has a reverse spillover effect on GDP, and economic growth affected by energy use efficiency, it is manifested as diminishing returns to scale.

The estimated result of $\beta_{l}$ in equation (3) shows that the economic growth mode is intensive. If per capita GDP increases by $1 \%$, per capita energy consumption will increase by $2.0813 \%$. In the long run, per capita energy consumption will begin to decline with the growth of per capita GDP only when the per capita GDP exceed 17,963,497 . It means that in accordance with China's current industrial structure, energy policy, and production mode, it is impossible to reduce energy consumption by simply relying on the improvement of economic development.

The coefficient of the urbanization rate is positive and significant at $10 \%$ significance level. It means that the increase in urbanization rate will increase the total energy consumption. If the urbanization rate increases by 1 percentage, per capita energy consumption will increase by $0.2000 \%$. The coefficient of trade openness is positive and significant at $10 \%$ significance level. If the trade openness increases by 1 percentage, per capita energy consumption will increase by $0.0300 \%$. The results mean that although China's economic growth is largely dependent on import and export trade, but the impact of trade on energy consumption is relatively weak.

\section{Conclusion}

China has successively proposed the Belt and Road Initiative, promoted urbanization and implemented supply-side structural reforms. Since China is a traditional energy demand country, the relationship between energy consumption and economic growth has attracted more and more attention from academic circles and Chinese government decision-making departments. This paper establishes a simultaneous equation model based on growth theory to empirically study the relationship between energy consumption, GDP, capital stock, urbanization and trade openness in China with the use of panel data of 30 provincial administrative regions from 1990 to 2018. The estimation results of simultaneous equation show that:

1) There is a long-term stable two-way causal relationship between energy consumption and GDP.

2) The environmental Kuznets curve hypothesis is valid in China.

3) The energy consumption has a reverse spillover effect on GDP.

4) The economic growth expressed as a production function is diminishing returns to scale.

5) The Increase in urbanization leads to a slight risen in energy consumption.

6) The increase in trade openness will increase energy consumption, but the impact is relatively weak.

It is concluded from the empirical analysis results that China's GDP and energy consumption are endogenous causal relationship within the economic system under the condition of controlling capital stock, urbanization rate and trade openness. The study also finds that the growth of energy consumption shows a negative influence on economic development under the condition of scarce resources, the extensive production mode, environmental damage and pollution. China's inefficient energy use leading to diminishing returns to scale in economic growth. The above results not only conform to 
the theoretical relationship between economic growth and energy consumption, but also conform to the current status and characteristics of China's economic development. Energy is an indispensable important input factor for economic development. The resource protection policies proposed to reduce the amount of energy consumption would limit the speed of economic growth. At the same time, the fluctuations of energy prices and the shortage of energy will further restrict China's economic growth. Therefore, the Chinese government should correctly guide the transformation of the entire social production mode, improve the efficiency of energy use, reduce environmental pollution in the process of energy consumption, and reduce dependence on fossil fuel. Otherwise, the constraint effect of growing energy consumption on economic growth will continue to expand. In order to ensure sustainable high speed economic growth, it is necessary to gradually improve the current energy consumption structure, diversify channels of importing energy, research and develop new type of safe and clean energy to ensure adequate energy supply. To avoid the adverse impact of energy on economic growth, the Chinese government needs to adopt more comprehensive policies to transform the current production mode from extensive to intensive.

\section{References}

[1] Kraft J, Kraft A. On the relationship between energy and GNP [J]. The Journal of Energy and Development. 1978 Spring; 3(2): 401-403.

[2] Akarca A T, Long II T V. Energy and employment: a time-series analysis of the causal relationship [J]. Resources and Energy. 1979 Oct-Nov; 2(2-3): 151-162.

[3] Akarca A T, Long T V. On the relationship between energy and GNP: a reexamination [J]. The Journal of Energy and Development. 1980 Spring; 5(2): 326-331.

[4] Eden S H, Hwang B K. The relationship between energy and GNP: further results [J]. Energy Economics. $1984 \mathrm{Jul} ; 6(3): 186-190$.

[5] Yu E S H, Choi J Y. The causal relationship between energy and GNP: an international comparison [J]. The Journal of Energy and Development. 1985 Spring; 10(2): 249-272.

[6] Erol U, Eden S H. Time series analysis of the causal relationships between US energy and employment [J]. Resources and Energy. 1987 Jun; 9(1): 75-89.

[7] Eden S H, Jin J C. Cointegration tests of energy consumption, income, and employment [J]. Resources and Energy. 1992 Sep; 14(3): 259-266.

[8] Masih A M M, Masih R. Energy consumption, real income and temporal causality: results from a multicountry study based on cointegration and error-correction modelling techniques [J]. Energy Economics. 1996 Jul; 18(3): 165-183.

[9] Masih A M M, Masih R. On the temporal causal relationship between energy consumption, real income, and prices: some new evidence from Asian-energy dependent NICs based on a multivariate cointegration/vector error-correction approach [J]. Journal of Policy Modeling. 1997 Aug; 19(4): 417440.

[10] Glasure Y U, Lee A R. Cointegration, error-correction, and the relationship between GDP and energy: The case of South Korea and Singapore [J]. Resource and Energy Economics. 1998 Mar; 20(1): 17-25.

[11] Asafu-Adjaye J. The relationship between energy consumption, energy prices and economic growth: time series evidence from Asian developing countries [J]. Energy Economics. 2000 Dec; 22(6): 615-625.

[12] Hondroyiannis G, Lolos S, Papapetrou E. Energy consumption and economic growth: assessing the evidence from Greece [J]. Energy Economics. 2002 Jul; 24(4): 319-336.

[13] Soytas U, Sari R. Energy consumption and GDP: causality relationship in G-7 countries and emerging markets [J]. Energy Economics. 2003 Jan; 25(1): 33-37.

[14] Altinay G, Karagol E. Structural break, unit root, and the causality between energy consumption and GDP in Turkey [J]. Energy Economics. 2004 Nov; 26(6): 985-994.

[15] Ang J B. CO2 emissions, energy consumption, and output in France [J]. Energy Policy. 2007 Oct; 35(10): $4772-4778$.

[16] Ang J B. CO2 emissions, research and technology transfer in China [J]. Ecological Economics. 2009 Aug; 68(10): 2658-2665. 
[17] Halicioglu F. An econometric study of $\mathrm{CO} 2$ emissions, energy consumption, income and foreign trade in Turkey [J]. Energy Policy. 2009 Mar; 37(3): 1156-1164.

[18] Jalil A, Mahmud S F. Environment Kuznets curve for CO2 emissions: a cointegration analysis for China[J]. Energy Policy. 2009 Dec; 37(12): 5167-5172.

[19] Apergis N, Payne J E. CO2 emissions, energy usage, and output in Central America[J]. Energy Policy. 2009 Aug; 37(8): 3282-3286.

[20] Apergis N, Payne J E. The emissions, energy consumption, and growth nexus: evidence from the commonwealth of independent states[J]. Energy Policy. 2010 Jan; 38(1): 650-655.

[21] Hossain M S. Panel estimation for CO2 emissions, energy consumption, economic growth, trade openness and urbanization of newly industrialized countries[J]. Energy Policy. 2011 Nov; 39(11): 6991 6999. 